Men and women placed in leadership positions communicated information about their skills and abilities to their subordinates. Although leaders' perceptions of their abilities, group members' knowledge of their leader's abilities, and the specific skills needed by the leader were all manipulated in the experimental setting, selfpresentations of ability were primarily determined by sex role stereotypes rather than by situational factors. Results indicated that (1) male leaders emphasized their social influence and task abilities; (2) female leaders emphasized their interpersonal, socioemotional abilities; and (3) group members felt task ability, as compared to interpersonal ability, was a far more important skill for a leader to possess. It was concluded that sex differences in male and female leadership behavior may be due to self-presentational conformity to sex roles, and that this conformity enhances males' leadership effectiveness while detracting from females' leadership effectiveness.

\title{
SELF-PRESENTATIONAL DETERMINANTS OF SEX DIFFERENCES IN LEADERSHIP BEHAVIOR
}

\author{
DONELSON R. FORSYTH \\ Virginia Commonwealth University \\ BARRY R. SCHLENKER \\ University of Florida \\ MARK R. LEARY \\ University of Texas at Austin \\ NANCY E. McCOWN \\ University of Florida
}

Studies of group dynamics suggest that women and men in groups tend to display abilities and skills that are quite con-

AUTHORS' NOTE: The present study was partially supported by NSF Grant \#BNS77-08182 to the second author.

SMALL GROUP BEHAVIOR, Vol, 16 No. 2, May 1985 197-210

- 1985 Sage Publications, Inc. 
sistent with prevailing sex role stereotypes. As early as 1956 Strodtbeck and Mann reported that men in groups provide orientation, opinions, and directions designed to lead the group toward goal-attainment, whereas women emphasize group solidarity, reduction of group tension, and avoidance of intragroup antagonism. Piliavin and Martin (1978) have recently replicated these findings and conclude that men and women, in both same- and mixed-sex groups, perform behaviors prescribed by the traditional male-female stereotypes: Women are interpersonally oriented whereas men are task-oriented.

Although the sex role consistency of men's and women's behavioral influences many aspects of group dynamics, the relationship between sex roles and leadership behavior seems particularly marked. Although theory and research indicates that both task skills and socioemotional skills are needed for effective leadership (for example, Stogdill, 1974), most group members assume that women are less effective leaders because they lack the requisite skills of assertiveness, interpersonal dominance, and problem-solving ability (Jacobson and Effertz, 1974). Men, however, are viewed as "natural" leaders because they are assumed to be able to organize and guide groups toward desirable goals.

Even though recent work indicates that men and women are not differentially effective as leaders (Brown, 1979), these assumptions of sex differences in leadership behavior still influence group members' perceptions and the leader's own perceptions. For example, Ferber et al. (1979) surveyed a number of university employees and found that the overwhelming majority preferred male rather than female bosses. Similarly, after sampling the attitudes of a number of male managers, Rosen and Jerdee (1978) concluded most rated females more negatively than males when judging aptitudes, leadership skills, motivation, and general temperament. Focusing on women and men in managerial positions, Deaux (1979) presents evidence that indicates men more than women believe they perform their job well. Indeed, in comparison to women, 
men attributed their successful attainment of the leadership position to their ability rather than good luck. Taken in combination, these studies indicate sex roles work to (1) restrict the range of male and female leadership behavior-eliciting an interpersonal orientation from females and a task orientation from males-and (2) create differences in group members' perceptions of the qualifications of female and male leaders.

In contrast with these conclusions, other research indicates that when situational pressures for particular behaviors conflict with the prescriptions of traditional sex role stereotypes, the influence of sex roles decreases as individuals adapt their behavior to meet the needs of the situation. Yockey (1978), for example, has recently demonstrated that in social situations women tend to display traditional sex role behavior, but in task situations women shift in the direction of "masculine" behaviors. Similarly, Zanna and Pack (1975) found that women's self-descriptions are inconsistent with sex role stereotypes when such self-presentations provide effective means of reaching desired goals. When applied to leadership, this research suggests that women leaders who must engage in behaviors typically ascribed to males may-through their self-presentations (Goffman, 1959)-lay claim to characteristics and attributes that are inconsistent with traditional sex roles.

This tension between the demands of the leadership situation and the prescriptions of traditional sex role stereotypes was examined in the current investigation by manipulating (1) the leader's perception of her or his abilities, (2) the group members' knowledge of their leader's abilities, and (3) the specific skill needed by the group leader. After assembling in four-person same-sex groups, leaders were selected on the basis of scores on a bogus leadership skills inventory. Onethird were told they had high interpersonal skills; one-third were told they had high task ability; and the remaining third were told they had both task and interpersonal skills. Next, the leaders were led to believe that the rest of the group had been told about their scores or that their followers were unin- 
formed. In addition, the groups were told that successful performance on a series of experimental group tasks was closely related to the abilities of their leader. One-half of the groups were told success in the experiment would depend upon their leader's ability to effectively solve the tasks given the group, while the remaining groups were informed that success depended upon the leader's ability to maintain smooth interpersonal relations in the group. Before actually working on any tasks, leaders were given the opportunity to describe their skills and abilities using a self-description questionnaire.

The leadership situation was designed to place the men and women leaders in a complex self-presentational dilemma. If, as much previous research suggests (Piliavin and Martin, 1978; Strodtbeck and Mann, 1956), sex differences in leadership behavior are relatively intractable, then leaders' selfpresentations should conform to sex role stereotypes: Males should present themselves as task-oriented and women should present themselves as interpersonally oriented irrespective of task demands, perceived ability, and group knowledge. If, however, situational information overwhelms the importance of maintaining sex role consistency, leaders should claim to possess those attributes needed in the current situation provided, of course, (1) they have demonstrated they possess these skills by their test performance or (2) they believe that the group members will not be made aware of their scores (cf. Schlenker, 1975).

\section{METHOD}

\section{SUBJECTS}

Seventy-two females and seventy-one male introductory psychology students participated in four-person, same-sex groups and were requested not to sign up with friends for the same session. Groups were run by one male and one female experimenter. 


\section{PROCEDURE}

Subjects were assigned to one cell of a two (Ability Needed in the Group: Task or Interpersonal) by three (Ability Possessed: Task, Interpersonal, or Both) by two (Score Anonymity: Public or Private) factorial design, with the stipulation that no more than one member of the same group serve in the same cell. Subjects listened to tape-recorded instructions while seated in individual adjoining cubicles that prevented visual contact between them. The instructions stated that the purpose of the experiment was to examine group dynamics and that their group would also meet two subsequent times to work on a variety of group tasks. A leader, who would control all of the group activities in this and the remaining sessions, would be selected on the basis of scores on a Leadership Skills Inventory that would be completed shortly. It was clearly noted that in order to study how the characteristics of both the leader and the group members affect group interactions, the person selected as the leader would not necessarily have the highest (or even high) scores on the major relevant abilities. Thus selection as a leader did not automatically substantiate overly favorable self-presentations.

Subjects then completed the Inventory, which was a bogus but face-valid measure containing socioemotional, creativity, reasoning, and ingenuity problems. The inventory was sufficiently unstructured to ensure that subjects could not be certain of how well they had performed, and they were told it assessed both problem-solving (task) ability and interpersonal relations ability. While the experimenter was supposedly scoring the subjects' responses and selecting the leader for the group, subjects read the instruction booklet for the first task. The task was described as "like ones which frequently confront groups in real organizations," and once the task was completed, the group members would rate the leader's effectiveness. Subjects in the high Interpersonal Ability Needed condition read that the leader was to be rated on his or her ability to "establish positive interpersonal relations during the 
task," while the high Task Ability Needed instructions stated leaders were to be evaluated on their ability "to get the group the highest score possible on the task."

The results of the experimenter's tabulations were then distributed, and all subjects learned they had been selected to be the leader. The scores were controlled so that subjects read they possessed High Task Ability and slightly below average interpersonal ability ( 91 st versus 47 th percentile), High Interpersonal Ability and slightly below average task ability (91st versus 47 th percentile), or had performed very well on both the task and interpersonal portions of the inventory (91st and 93 rd percentiles, counterbalanced across subjects). In addition, subjects' scoring sheets stated that group members' scores on the inventory would be kept private and would not be known by the other group members or that the scores would be public as the group members would exchange score sheets to allow them to learn of one another's abilities.

Subjects were then informed they would be exchanging personal information about themselves so as to establish the atmosphere of a nonartificial group situation in which members know one another. To accomplish this end, subjects completed an Information Exchange Questionnaire that they believed would be circulated around the group and that requested selfratings on 42 7-point bipolar adjective scales and attitudes toward the group situation on 15-point scales. Subjects next completed a manipulation check questionnaire (15-point scales), which they were told would be seen only by the experimenter, and were then debriefed.

\section{RESULTS}

\section{MANIPULATION CHECKS}

Questionnaire responses were submitted to two (Ability Needed) by three (Ability Possessed) by two (Score Anonymity) 
analysis of variance. All manipulations were effective because: (1) Subjects in the public scores condition believed that the other group members would see their scores whereas those in the private scores condition believed the others would not, $\mathrm{p}<.001, \mathrm{Ms}=13.0$ and 3.9 , respectively; (2) subjects correctly recognized whether they would be later evaluated on task or interpersonal ability, $\mathrm{p}<.001, \mathrm{Ms}=10.9$ and 6.0; and (3) A MANOVA using Pillai's Trace as the approximation of $F$ revealed a main effect of Ability Possessed on the four ability manipulation checks presented in Table 1, F (8, 236) $=59.59, \mathrm{p}<.001$.

\section{SEX DIFFERENCES IN SELF-PRESENTATIONS}

The pooled within-cell correlations of the 42 bipolar adjective scales on the Information Exchange Questionnaire were submitted to principal axes factor analysis with varimax rotations. The three factors retained accounted for $60.8 \%$ of the common variance and had eigenvalues of 11.0, 2.5, and 2.3. The first factor included subjects' presentations of personal prominence (potency plus competence) on adjectives such as powerful, influential, dominant, and skilled. The second factor represented accommodativeness toward others and included such items as self-disclosing, open, and moving toward others. The final factor, social attractiveness, consisted of such adjectives as fair, truthful, responsible, and pleasant. These three dimensions correspond quite closely to earlier distinctions drawn from investigations of leadership behavior (for example, Bales, 1970; Stodgill, 1974; Shaw, 1976). The first factor pertains directly to the leader's ability to move the group toward successful task accomplishment, whereas the latter factors pertain to different facets of the maintenance of interpersonal relationships within the group.

Standardized factor scores were computed on each of these factors and were submitted to a five-factor split-plot ANOVA (Ability Possessed by Ability Needed by Anonymity by Sex 
TABLE 1

Effects of the Ability-Possessed Manipulation on

Ratings of Personal Ability

\begin{tabular}{lcccc}
\multicolumn{1}{c}{ Measure } & \multicolumn{4}{c}{ Abjlity Possessed } \\
\cline { 2 - 5 } & Task & $\begin{array}{c}\text { Inter- } \\
\text { Personal }\end{array}$ & Both & Ratio \\
\hline Task Ability & $14.5_{\mathrm{a}}$ & $7.2_{\mathrm{C}}$ & $13.6_{\mathrm{b}}$ & $159.75^{* *}$ \\
Interpersonal Skilis & $9.9_{\mathrm{b}}$ & $14.3_{\mathrm{a}}$ & $13.5_{\mathrm{a}}$ & $189.70^{* *}$ \\
Perceived Task Ability & $11.6_{\mathrm{a}}$ & $9.1_{\mathrm{b}}$ & $11.4_{\mathrm{a}}$ & $29.70^{\star *}$ \\
Percelved Interpersonal Skill & $10.4_{\mathrm{b}}$ & $11.5_{\mathrm{a}}$ & $11.4_{\mathrm{a}}$ & $5.56^{*}$
\end{tabular}

NOTE: HIgher scores indicate more favorable ratings. Degrees of freedom = $2 / 120$. For any single Item, means without a common subscript differ at $p<.05$. $*_{p}<.05 ; *{ }^{*} p<.01$.

by Self-Presentation Dimension, with the latter as a withinsubjects factor). This analysis is not only statistically advisable because each subject provided self-presentations on each of the dimensions, but it allows the examination of effects of the independent variables on patterns of self-presentations across different dimensions.

A Sex by Dimension interaction, $F(2,240)=10.03, \mathrm{p}<$ .01 , and a four-way interaction of Sex, Ability Needed, Score Anonymity, and Dimension, $F(2,240)=3.47, \mathrm{p}<.05$, reached significance. In only one instance did the four-way interaction qualify the Sex by Dimension interaction by suggesting subjects were basing their self-presentations on the demands of the situation. In the Score Known-Interpersonal Relations Needed condition, males did tend to emphasize their attractiveness nonsignificantly more than their prominence $(-0.11$ versus +.04 , n.s.). More typically, subjects' claims and disclaimers did not reflect the influence of situational 
TABLE 2

Males' and Females' Self-Presentations

\begin{tabular}{llcc}
\hline & & & \\
& & & \\
& Drominension & & \\
& & Accommodativeness & Attractiveness \\
Males & $+0.159 \mathrm{ab}$ & $-0.233_{\mathrm{c}}$ & $-0.359 \mathrm{c}$ \\
Females & $-0.159 \mathrm{bc}$ & $+0.233_{\mathrm{a}}$ & $+0.359 \mathrm{a}$
\end{tabular}

NOTE: Higher scores indicate greater emphasis. Means without a common subscript differ at $p<.05$ by Duncan's Multiple Range Test.

self-presentational demands, but instead conformed to sex role stereotypes. The means for the Sex by Dimension interaction shown in Table 2 indicate that (1) females presented themselves more positively than males on both the accommodativeness and attractiveness dimensions, ps $<.05$; (2) males presented themselves more positively on the prominence dimension than on the remaining dimensions, $\mathrm{p}<.05$; and $(3)$ prominence was the dimension least emphasized by females, $\mathrm{p}<.05$.

Thus although males' and females' self-presentations were relatively unaffected by either score anonymity or the skills needed factors, the sex differences obtained were consistent with prior research on self-presentations (Schlenker, 1975) and other behavior (Shaw, 1976) in group situations. Females apparently relied on claiming stereotypic attributes of accommodativeness and attractiveness irrespective of the levels of the independent variables, perhaps because they believed they could substantiate such claims later through their behaviors or because they believed the other female group members would be more impressed by claims to interpersonal rather than task ability. Males, on the other hand, tactically selected the stereotypic pattern that they believed would be most readily accepted and respected by males; in general, males flagrantly 
disregarded interpersonal dimensions, instead staking claim to prominence.

\section{ANCILLARY FINDINGS}

Self-presentations. Only one other effect reached significance on the self-presentation scores. The Ability Possessed by Dimension interaction, $F(4,240)=2.40, p<$ .05 , presented in Table 3 , indicated that subjects who received high scores on only one of the abilities accentuated the dimension(s) that was most relevant to the ability they believed they possessed and deemphasized the dimension most relevant to the ability they lacked. Interpersonal ability subjects emphasized their attractiveness and deemphasized their prominence, whereas task ability subjects tended to do the reverse. Subjects who believed they possessed both abilities generally fell intermediate, apparently secure in their own dual accomplishment and not wishing to risk overly positive claims that might be viewed as egotistical and lead to disapproval (Schneider, 1969). Contrary to predictions, anonymity of past scores did not qualify this effect.

Importance of leadership skills. The Information Exchange Questionnaire also included ten items pertaining to the judged importance of abilities usually attributed to womeninterpersonal skills-and abilities usually attributed to mentask ability. These items assessed (1) Personal expectations of doing well on the problems and establishing positive relations; (2) expectations of how well the group would do on each facet; (3) the importance for the group and for the leader to do well on each; and (4) feelings of personal responsibility for achieving each.

A MANOVA performed on the five task-related items revealed main effects of Ability Possessed, F $(10,232)=3.97$, 
TABLE 3

Effects of Ability Possessed on Self-Presentations

Abil1ty Possessed

Dimension

Pominence Accommodativeness Attractiveness

$\begin{array}{llll}\text { Task } & +0.235 \mathrm{a} & +0.079 \mathrm{ab} & -0.56 \mathrm{ab} \\ \text { Interpersonal } & -0.265 \mathrm{~b} & -0.167 \mathrm{ab} & +0.221 \mathrm{a} \\ \text { Both } & +0.030 \mathrm{ab} & +0.088 \mathrm{ab} & -0.165 \mathrm{ab}\end{array}$

NOTE: Higher scores indlcate greater emphasis. Means without a common subscript differ at $p<.05$ by Duncan's Multiple Range Test.

$\mathrm{p}<.001$, and Ability Needed, $F(5,116)=5.05, \mathrm{p}<.001$. Table 4 presents the items on which the Ability Possessed main effects also reached univariate significance. Subjects who believed they had high task ability or both abilities generally anticipated better personal and group performance on the problems and rated the importance of doing well on them higher. Similarly, subjects who believed that task rather than interpersonal skills would be needed rated task ability as more important, felt it was more important for the group to perform well, and reported that their personal performance would be better ( $p s<.05$ ). Thus both the task strengths (or weaknesses) these subjects believed they possessed and the evaluative demands of the situation affected their self-efficacy reports and the abilities they valued. Through such selective valuation, a positive aura can be maintained around oneself (Rosenberg, 1968).

In contrast, a MANOVA performed on the five items dealing with interpersonal relations revealed no significant effects, showing that evaluative selectivity was limited to task-relevant items. Subjects apparently believed that a leader plays a more salient role in establishing or impeding task performance than interpersonal relations. 
TABLE 4

Effects of Ability Possessed on Expectations and Importance of Performance

Perceptions of Group Situation

Ablilty Possessed

\begin{tabular}{ccc}
\multicolumn{3}{c}{ Ability Possessed } \\
Task & $\begin{array}{c}\text { Inter- } \\
\text { Personal }\end{array}$ Both & Ratio
\end{tabular}

How well will you perform on the task?

$12.3 \mathrm{a}$

$11.1_{b}$

$12.1 \mathrm{a} \quad 6.07^{\star}$

How well will group perform on task?

$12.1 \mathrm{~b}$

$11 \cdot 1 \mathrm{c}$

$13.0 \mathrm{a} \quad 7.15^{\star}$

Importance of good task performance

$10.7 \mathrm{ab}$

$10.3 \mathrm{~b}$

$11.9 \mathrm{a} 3.19^{*}$

Importance of task ability

$13 \cdot 3 a$

$12.0_{\mathrm{b}}$

$12.6_{b} \quad 6.86^{*}$

NOTE: Higher scores Indlcate more favorable ratings. Degrees of freedom = $2 / 120$. For any single item, means without a common subscript differ at $p<.05$ by Duncan's Multiple Range Test.

$\star_{p}<.05$.

\section{DISCUSSION}

Although self-presentations indicated leaders emphasized those attributes they believed they possessed and deemphasized those they believed they lacked, neither the knowledge that certain skills were needed nor the anonymity of one's skills influenced self-presentations. Instead, sex role stereotypes dominated these situational factors as both men and women patterned their interpersonal information exchange to be consistent with sex-linked characteristics. The male leaders, irrespective of their perceptions of their own abilities, their audiences' knowledge of these abilities, and the skills needed in the experimental setting, consistently described themselves as "typical" males through claims of power, influence, skill, and dominance. Conversely, female leaders' self-descriptions emphasized their openness toward others, social attractiveness, and general willingness to get along with others-all characteristics typically attributed to women in both leadership and nonleadership positions. 
These results are quite relevant to current discussions of the relative worth of male versus female leaders (Brown, 1979). As Stogdill (1974) points out, a group leader must be able to do two things: Hold the group together as a cohesive unit and move the group in the direction of desired goals. Unfortunately, the first of these abilities seems to be viewed as only minimally important by group members. The subjects in the current study, for example, felt their group would perform more effectively if they believed they possessed task ability rather than interpersonal ability. Both men and women leaders assumed task skills were more important qualities for a leader to possess than socioemotional skills, even when specifically informed that interpersonal competence was the critical ability needed in the current situation. Significantly, these devalued interpersonal skills are exactly those abilities most frequently attributed to women and, in this research, claimed by women. On the other hand, the equally important but more valued task skills are both attributed to and claimed more frequently by men.

Given the finding that task abilities are more highly appraised by group members than interpersonal/socioemotional skills, this study suggests that the males would have been more effective in securing a position of leadership via selfpresentations because the male sex role they conformed to emphasizes dominance and task proficiency. In contrast, the females'emphasis on social skills does not seem to be an effective way for a leader to inspire trust and confidence in subordinates. Although other group members may be more willing to believe self-presentations that are in line with sex roles, minimizing one's task or interpersonal abilities simply to maintain sex role consistency undermines leadership effectiveness and further reinforces existing assumptions about sex differences in leadership behavior. As Eagly (1978) concluded in her analysis of the greater conformity and persuasibility of women as compared to men, this research suggests that the currently observed differences in male and female group behavior may be due primarily to self-presentational conformity to sex roles. 


\section{REFERENCES}

BALES, R. F. (1970) Personality and Interpersonal Behavior. New York: Holt, Rinehart \& Winston.

BROWN, S. M. (1979) "Male versus female leaders: a comparison of empirical studies." Sex Roles 5: 595-611.

DEAUX, K. (1979) "Self-evaluations of male and female managers." Sex Roles 5: $571-583$.

EAGLY, A. H. (1978) "Sex differences in influenceability." Psych. Bull. 85: 86-1 16.

FERBER, M., J. HUBER and G. SPITZE (1979) "Preference for men as bosses and professionals." Social Forces 58: 466-476.

GOFFMAN, E. (1959) The Presentation of Self in Everyday Life. New York: Doubleday.

JACOBSON, M. B. and J. EFFERTZ (1974) "Sex roles and leadership perceptions of the leaders and the led." Organizational Behavior and Human Performance 12: 383-396.

PILIAVIN, J. A. and R. R. MARTIN (1978) "The effects of sex composition of groups on style of social interaction." Sex Roles 4: 281-296.

ROSEN, B. and T. H. JERDEE (1978) "Perceived sex differences in managerially relevant characteristics." Sex Roles 4: 837-843.

ROSENBERG, M. J. (1968) "Psychological selectivity in self-esteem," in C. Gordon and K. J. Gergen (eds.) The Self in Social Interaction. New York: John Wiley.

SCHLENKER, B. R. (1975) "Self-presentation: managing the impression of consistency when reality interfered with self-enhancement." J. of Personality and Social Psychology 32: 1030-1037.

SCHNEIDER, D. J. (1969) "Tactical self-presentation after success and failure." J. of Personality and Social Psychology 13: 262-268.

SHAW, M. E. (1976) Group Dynamics: The Psychology of Small Groups. New York: McGraw-Hill.

STODGILL, R. M. (1974) Handbook of Leadership. New York: Free Press.

STRODTBECK, F. L. and R. D. MANN (1956) "Sex role differentiation in jury deliberations." Sociometry 19: 3-11.

YOCKEY, J. M. (1978) "Role theory and the female sex role." Sex Roles 4: 917-927.

ZANNA, M. P. and S. J. PACK (1975) "On the self-fulfilling nature of apparent sex differences in behavior." J. of Experimental Social Psychology 11: 583-591.

Donelson R. Forsyth is Associate Professor of Psychology at Virginia Commonwealth University and is currently investigating social cognition and group processes.

Barry R. Schlenker is Professor and Director of the Social-Personality Psychology Program at the University of Florida. His research interests are in the areas of the self and self-presentation.

Mark R. Leary is Assistant Professor of Educational Psychology at the University of Texas at Austin. His research interests include self-presentation, social anxiety, and social cognition.

Nancy E. McCown is Research Analyst for KPC/Research, a subsidiary of Knight Publishing Company. 